\begin{tabular}{lccr} 
A R C H I V E & O F & M E C H A N I C A L & E N G I N E E R I N G \\
\hline VOL. LXIII & 2016 & Number 2
\end{tabular}

10.1515/meceng-2016-0013

Key words: underwater chain mooring, verification, real experiment, numerical simulation code

\title{
VERIFICATION OF A NUMERICAL SIMULATION CODE FOR UNDERWATER CHAIN MOORING
}

\begin{abstract}
Numerical simulation is an economical and effective method in the field of marine engineering. The dynamics of mooring cables has been analysed by a numerical simulation code that was created on a basis of a new element frame. This paper aims at verifying the accuracy of the numerical simulation code through comparisons with both the real experiments and a commercial simulation code. The real experiments are carried out with a catenary chain mooring in a water tank. The experimental results match the simulation results by the numerical simulation code well. Additionally, a virtual simulation of a large size chain mooring in ocean is carried out by both the numerical simulation code and a commercial simulation code. The simulation results by the numerical simulation code match those by the commercial simulation code well. Thus, the accuracy of the numerical simulation code for underwater chain mooring is verified by both the real experiments and commercial simulation code.
\end{abstract}

\section{Introduction}

One common characteristic of the marine facilities, no matter the floating wind turbine [1] or oil and gas production facilities [2] is the huge outline dimensions. A real experiment about the marine faculties is very expensive and difficult to carry out. Additionally, the complexity of the marine environment aggravates the difficulties of the real experiments. Therefore, virtual simulation codes becomes popular in the field of marine engineering. The underwater chain moorings is analysed by the simulation codes that is on a basis of the static analysis in most of the published papers. Both the hydrodynamic forces and the added mass effects are ignored [3-5]. Because the chain mooring is heave and move slowly, and the seabed is assumed to be flat and horizontal, the static chain modeling is established considering

* School of Mechanical Engineering, Pusan National University, Busan, 609-735, South Korea; E-mails: zhuxiangqian@pusan.ac.kr,wsyoo@pusan.ac.kr 
the computational efficiency in that era. However, with the application of the composite materials and the development of the computer technology [6], more accurate simulation codes are called to consider the hydrodynamic forces and added mass effects. Lumped mass modeling is a favoured choice in the dynamic analysis of towed cables [7-9]. The cables are divided into finite elements, and an element frame is needed for each element to convert sustained forces with respect to the inertial frame. Conventionally, the Euler angles and the Frenet frame are used as the element frame in published papers. However, singularities go with every Euler angle set when the first rotation is collinear with the third rotation [10]; and the Frenet frame is invalided in the cases when the cable is taut straight [11]. Therefore, Zhu proposed for a new element frame to simulate the chain mooring in [12,13]. This new element frame is created based on vectors of element orientation and relative velocity of fluid. Both the rotational transformation matrix and hydrodynamic drag forces are expressed efficiently with respect to the new element frame. The numerical simulation code is established in consideration of the stiffness and damping of the chain, apparent weight, hydrodynamic drag forces and the effect of added mass, so a more accurate simulation results can be obtained compared with the static analysis. This numerical simulation code is also used to model the cable fastening a floating spar platform [14]. However, even though this numerical simulation code has been verified with the commercial simulation code, its accuracy has never been verified with a real experiment. What's more, the cable modeling generated by this simulation code is only 60 metres in $[12,13]$, the cable modeling with a large size is appreciated.

Therefore, in this paper, the numerical simulation code is checked by two ways: (1) compared with the real experiments with a small size chain mooring; and (2) compared with a commercial simulation code with a large size chain mooring. The real experiments are carried out in a water tank. One end of the chain is fixed to the tank and the other end is connected to an $\mathrm{X}-\mathrm{Z}$ traversing device that moves with a constant speed. The experiment procedure is shown in Fig. 1. The water tank is made of transparent glasses so that motions of the chain can be recorded using a camera. Depending on the recorded video tape, the TEMA software gives out the velocities and positions of the marked points [15]. The system error of the experiment is also analysed in this paper, which includes the initial error and the method error. After being proofread, the experimental results are compared with the simulation results by the numerical simulation code. The comparison with the experiment indicates the numerical simulation code is competent to model a catenary chain moving in the fluid. Additionally, the accuracy of the numerical simulation code is verified by a commercial simulation code in 
the case when a long catenary chain bears the ocean wave and current. An external force vertically acts on the top end of the chain to model the loads coming from the floating platform. Linear wave theory is used to express the hydrodynamic loads generated by the X-directional wave and current. Finally, the simulation results by the numerical simulation code are compared with those by the commercial simulation code, ProteusDS [16]. The results show that the numerical simulation code is competent to simulate mooring cable with a large size.

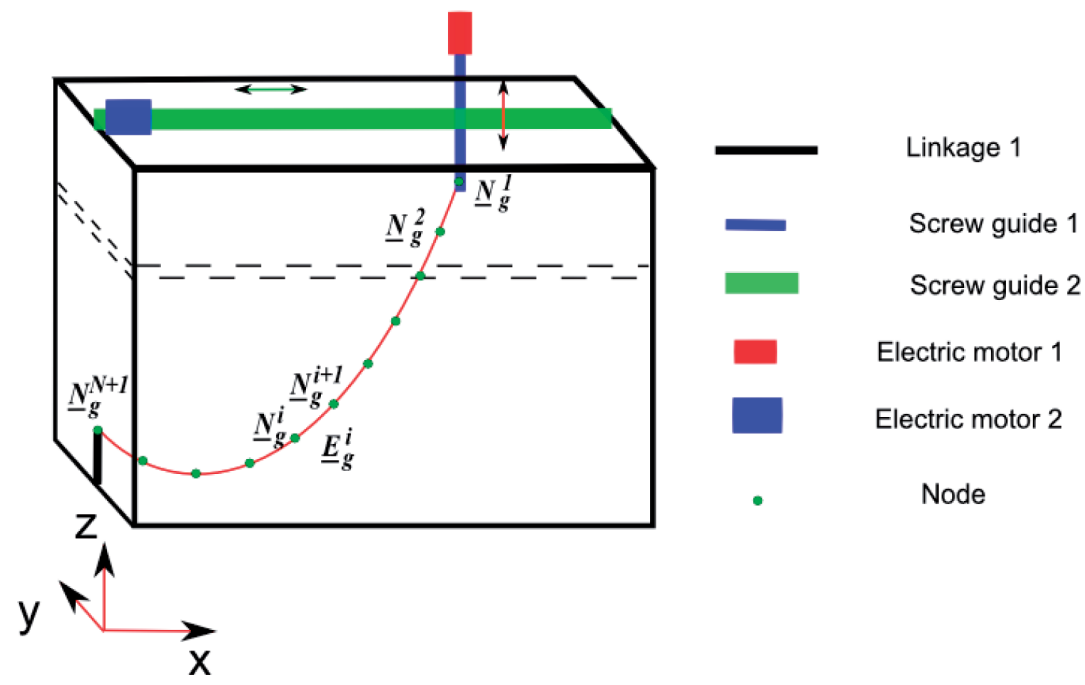

Fig. 1. Schematic diagram of the real experiment with chain mooring

\section{Numerical modeling of cable}

The theory of the proposed numerical simulation code is listed briefly, which is stated clearly in [12-14]. The lumped mass model is used to divide the cable into elements. $N_{g}^{i}$ and $E_{g}^{i}$ are the position vectors of the $i^{t h}$ node and element with respect to the initial frame, respectively. $V_{g}^{R}$ is the vector of the relative velocity of the fluid. The proposed element frame, based on vectors of element orientation and relative velocity of fluid, is defined as Eq. (1).

$$
\begin{aligned}
\bar{z}^{i} & =\frac{E_{g}^{i}}{\left\|E_{g}^{i}\right\|} \\
\bar{x}^{i} & =\frac{z^{i} V_{g}^{i}}{\left\|z^{i} V_{g}^{i}\right\|} \\
\bar{y}^{i} & =\tilde{z}^{i} \bar{x}^{i}
\end{aligned}
$$


The forces acting on the cable include the stiffness and damping of the cable $T_{b}^{i}$ and $D_{b}^{i}$, respectively; the hydrodynamic drag forces $F_{z}^{i}$ and $F_{y}^{i}$ and; the apparent weight $F_{W}^{i}$, as shown in Eq. (2)

$$
\begin{aligned}
T_{b}^{i} & =\frac{\pi d_{c}^{2}}{4} E \varepsilon_{b}^{i} \bar{z} \\
D_{b}^{i} & =C_{d} A^{i T}\left(\dot{N}_{g}^{i+1}-\dot{N}_{g}^{i}\right) \bar{z} \\
F_{z}^{i} & =\frac{\pi}{2} C_{f} \rho_{f} d^{i} l^{i}\left\|V_{g}^{R}\right\| \bar{z}^{T} V_{g}^{R} \\
F_{y}^{i} & =-\frac{1}{2} C_{n} \rho_{f} d^{i} l^{i}\left\|V_{g}^{R}\right\| \bar{x}^{T}\left(\tilde{z} V_{g}^{R}\right) \\
F_{W}^{i} & =\left(m_{c}^{i}-m_{f}^{i}\right) g
\end{aligned}
$$

where $\varepsilon_{b}^{i}$ and $l^{i}$ represent the is the axial strain and element length of the $i^{\text {th }}$ element. The masses of the cable and the displaced fluid for the $i^{\text {th }}$ element are $m_{c}^{i}$ and $m_{f}^{i}$, as given by Eq. (3).

$$
\begin{aligned}
& \varepsilon_{b}^{i}=\frac{l^{i}-l_{0}^{i}}{l_{0}^{i}} \\
& l^{i}=\sqrt{E_{g}^{i T} E_{g}^{i}} \\
& m_{c}^{i}=\frac{\pi d_{c}^{2}}{4} l_{0}^{i} \rho_{c} \\
& m_{f}^{i}=\frac{\pi d_{c}^{2}}{4} l_{0}^{i} \rho_{f}
\end{aligned}
$$

Mass matrixes of the nodes $M_{I}^{i}$ with respect to the initial frame are expressed by mass matrixes of the elements $M_{b}^{i}$ with respect to element frame, as shown in (4). $C_{A}$ is the coefficient of the added mass. The effect of added mass along the cable axial is ignored.

$$
\begin{aligned}
& M_{b}^{i}=\left[\begin{array}{ccc}
m_{c}^{i}+C_{A} m_{f}^{i} & 0 & 0 \\
0 & m_{c}^{i}+C_{A} m_{f}^{i} & 0 \\
0 & 0 & m_{c}^{i}
\end{array}\right] \\
& M_{I}^{i}=\frac{1}{2} A^{i-1} M_{b}^{i-1} A^{i-1}{ }^{T}+\frac{1}{2} A^{i} M_{b}^{i} A^{i} \quad{ }^{T}
\end{aligned}
$$


Finally, the governing equation for the $i^{\text {th }}$ node is defined by the forces acting on the $(i-1)^{t h}$ and $i^{t h}$ elements, as given by Eq. (5).

$$
M_{I}^{i} \ddot{N}_{g}^{i}=A^{i}\left(T_{b}^{i}+D_{b}^{i}+\frac{1}{2} F_{D}^{i}\right)-A^{i-1}\left(T_{b}^{i-1}+D_{b}^{i-1}-\frac{1}{2} F_{D}^{i-1}\right)+\frac{1}{2}\left(F_{W}^{i}+F_{W}^{i-1}\right)
$$

\section{Verification with real experiments}

\subsection{Experimental setting}

Simulation results by the numerical simulation code are verified with the real experiment that is carried out with a catenary chain in a water tank $(2700 \mathrm{~mm} \times 2300 \mathrm{~mm} \times 1650 \mathrm{~mm})$. The water depth is $1435 \mathrm{~mm}$. The top end of the chain moves with an X-Z traversing device, which moves with a constant speed, as shown in Fig. 2a. To make sure the chain does not touch the bottom of the tank, the other end of the chain is fixed at a point that is above the bottom with a height of $720 \mathrm{~mm}$. The motion of the chain is reflected by six marked points, which are pasted on the chain with respect to the chain span, as shown in Fig. $2 \mathrm{~b}$. In here, the 'C030' indicates the

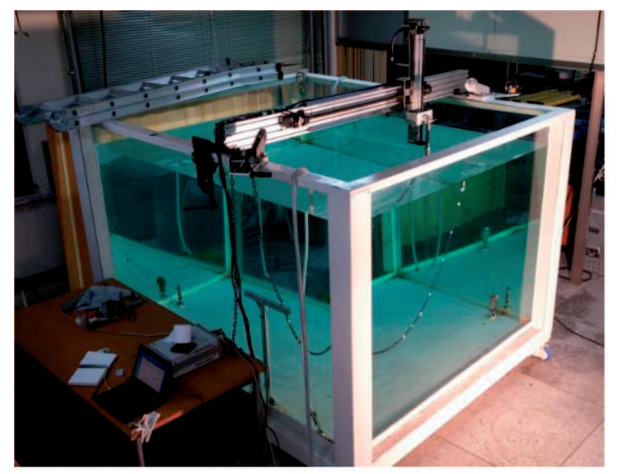

(a) $\mathrm{X}-\mathrm{Z}$ traversing device and water tank

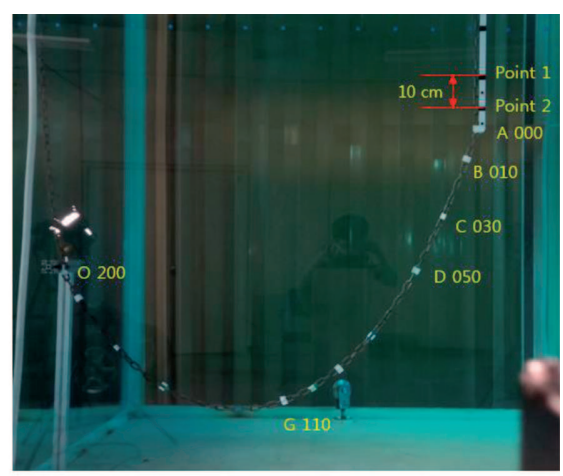

(b) Marked points on chain mooring

Fig. 2. Experimental setting

distance between the top end and the Point $\mathrm{C}$ is $300 \mathrm{~mm}$. In order to identify the effect of the reflection of the light, Point 1 and Point 2 are marked on the guild-bar with a vertical distance of $100 \mathrm{~mm}$. The guide bar moves from the left to the right side of the water tank with a speeds of 50 and $100 \mathrm{~mm} / \mathrm{s}$, respectively. The motions of the chain are recorded by a camera during experiments. Table 1 lists the properties of the chain mooring used in experiment. 
Properties of chain in real experiment

\begin{tabular}{|c|c|c|}
\hline Parameters & Magnitude & Unit \\
\hline Length & 2000 & $\mathrm{~mm}$ \\
\hline Mass & 1105 & $\mathrm{~g}$ \\
\hline Elastic Modulus & 211 & $\mathrm{GPa}$ \\
\hline Drag Coeff. & 2 & \\
\hline Added mass & 1 & \\
\hline Diameter & 9.5 & $\mathrm{~mm}$ \\
\hline Element No. & 20 & \\
\hline
\end{tabular}

\subsection{Post-processing}

Because the hydrodynamic drag force in the numerical simulation code is expressed using the Morison's equation, which is a semi-empirical equation, the hydrodynamic coefficients are defined from an experiment. In here, a vertical chain is used to judge these coefficients. The top of the chain is fixed to the $\mathrm{X}-\mathrm{Z}$ traversing device that moves with a constant speed of $50 \mathrm{~mm} / \mathrm{s}$. The bottom of the chain is free, and is marked to track its displacements during the experiment, as shown in Fig. 3a. The coefficients are judged by matching the X-displacement of the marked points from the numerical simulation code with that from the experimental results. Several virtual simulations are done with different coefficients, the simulation results match the experimental results well when the drag coefficient being 2 and the added mass coefficient being 1 , as shown by Fig. 3b. Therefore, the experiment with a catenary chain is carried out with the drag coefficient being 2 and the added mass coefficient being 1.

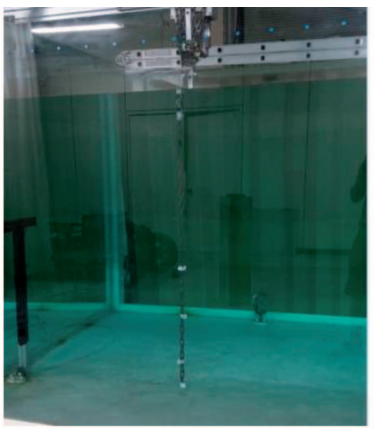

(a) Experiment to define the hydrodynamic coefficients

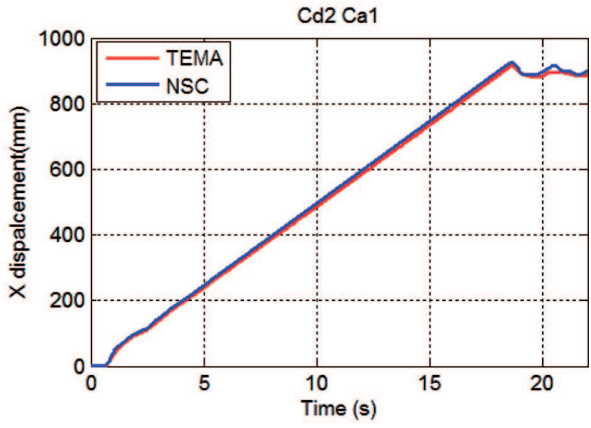

(b) Displacements of the marked point

Fig. 3. Definition of the hydrodynamic coefficients 


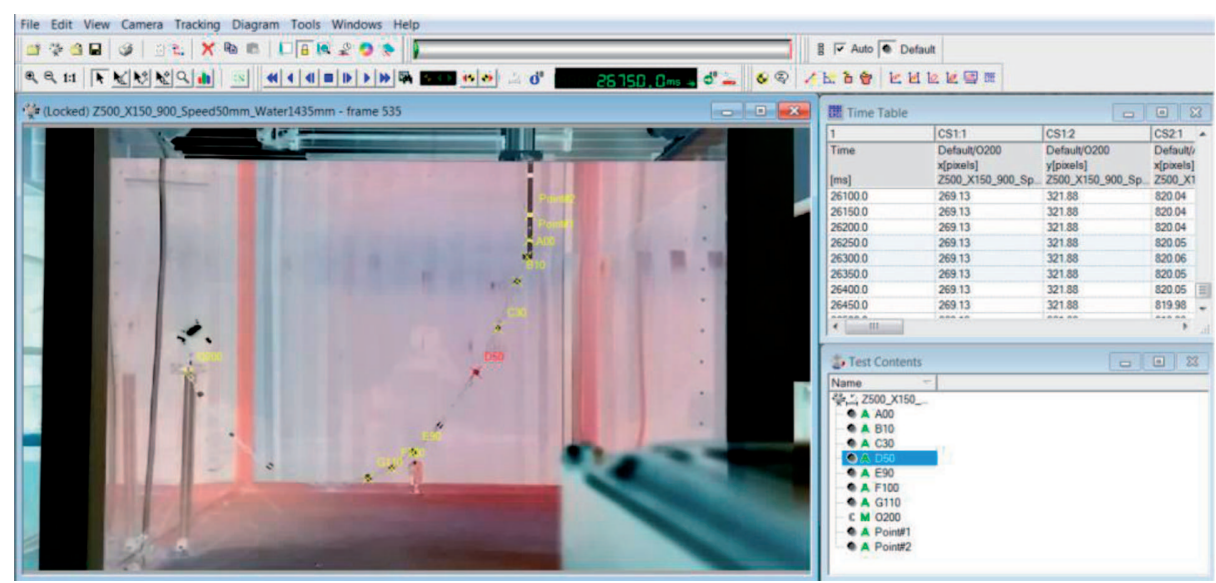

Fig. 4. Video tapes processed by TEMA Automotive software

Motions of the chain are recorded with a rate of 20 frames per second, and the video tapes are processed using TEMA software. Figure 4 shows the motions of the marked points proceeded by the TEMA. However, the obtained values are given with respect to the coordinate system of the TEMA, so the unit length of the coordinate system is identified in the post-processing. Point A moves from the left to the right with a distance of $750 \mathrm{~mm}$, the real distance between Point $\mathrm{A}$ and Point $\mathrm{O}$ are known, so the unit length in the X-direction can be identified according to the relationship between the measured values and the real distances with respect to:

1) the moving distance of the Point $\mathrm{A}$ in the $\mathrm{X}$-direction;

2) the distance between the Points $\mathrm{A}$ and $\mathrm{O}$ in the $\mathrm{X}$-direction before experiment; and

3) the distance between the Point $\mathrm{A}$ and $\mathrm{O}$ in the $\mathrm{X}$-direction after experiment.

Similarly, the unit length in the Z-direction is identified according to:

1) the distance between the Point 1 and Point 2 in the Z-direction;

2) the distance between the Point $\mathrm{A}$ and $\mathrm{O}$ in the Z-direction before experiment; and

3) the distance between the Point $\mathrm{A}$ and $\mathrm{O}$ in the Z-direction after experiment.

The simulation results from the numerical simulation code are compared with the experiment results, as shown in Fig. 5. The block circles denote the initial position of the catenary chain, which are identified from a static analysis; the red line represents experimental results post-processed by TEMA; the blue dot line denotes the simulation results by the numerical simulation code. 'NSC B' represents the simulation results of Point B by the numerical simulation code. Some differences are generated at the beginning 
of the comparison, such as the Z-directional displacements of the Point G. Because the chain is composed of chain elements with universal joints, the relative rotation between two adjacent chain elements should not be affected when pasting the marked points on the chain. It is difficult to locate these marked points on the correct positions. Additionally, although the Point A is set to traverse horizontally during the real experiments, the experimental results show that the Point A slightly drops proportional with the traversing distance. The reflection of light also generates error in the experiment. Therefore, the experimental results ought to be proofread.

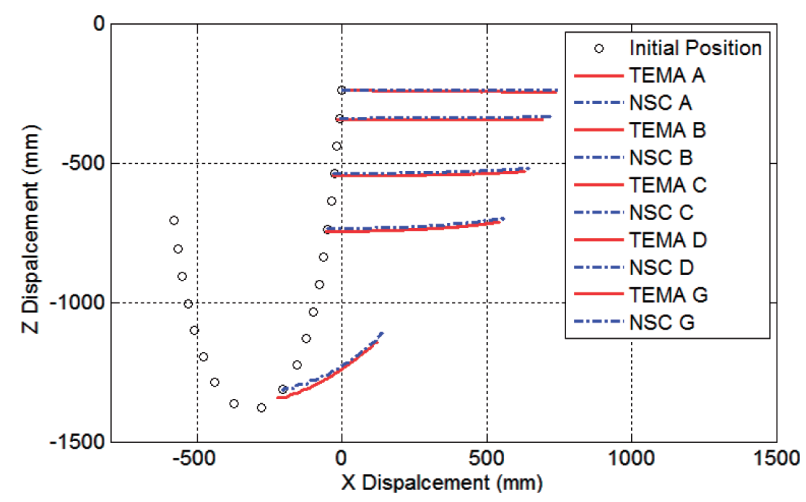

Fig. 5. Positions of the marked points before proofreading

\subsection{Proofreading}

System error, including the initial error and method error, always exists in the experimental results. The initial positions of the marked points are measured at the beginning of the experiment. The experimental results are proofread according to the measured values to make sure the initial positions of the marked points being identical in both the numerical simulation code and experiments. Additionally, the motions of chain captured by a camera also generates errors, because the light refracts when passes through different mediums. There is an inverse relationship between the refractive index and the sine function of the incidence angles [17]. Because the incidence angle is within $10^{\circ}$, the error can be simplified as a linear function of the moving distance [18]. This error can be proofread according to the Z-directional values of the moving Point $\mathrm{A}$, as shown in Fig. 6. Actually, the Point A moves horizontally with a constant speed, the Z-directional displacement drops because of the light reflection. A compensation function is generated according to the slope shown in Fig. 6. The corresponding values are added to the Z-directional values of the marked points according to Eq. (6). $X_{0}$ and $Z_{0}$ denote the original $X$ - and $Z$-displacements of the marked points. $\Delta Z$ is 
the corresponding value generated according to the compensation function. $k$ is the slope coefficient with a magnitude of $7.3 \mathrm{e}-3 \mathrm{~mm}$.

$$
\begin{aligned}
& Z=Z_{0}+\Delta Z \\
& \Delta Z=k X_{0}
\end{aligned}
$$

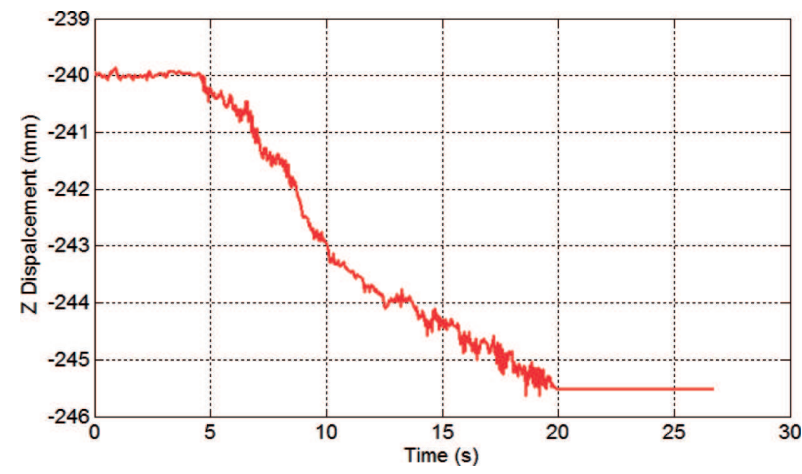

Fig. 6. Z-directional displacement of the Point A

Finally, the simulation results are compared with the real experimental results and shown in Fig. 7. The simulation results for Points $\mathrm{B}$ and $\mathrm{C}$ are slightly larger by numerical simulation code than those by the real experiments. The differences are caused by incorrect identification of the Points $\mathrm{B}$ and $\mathrm{C}$ in TEMA. The size and shape of the marked points should be clearly adequate when the video tape is analysed using TEMA software. The diameter of the marked point is approximately $13 \mathrm{~mm}$ in here, and the slight differences are easily generated in TEMA. Because these differences keep the same magnitude from the beginning to the ending, as shown in Fig. 7, there is no problem with the numerical simulation code.

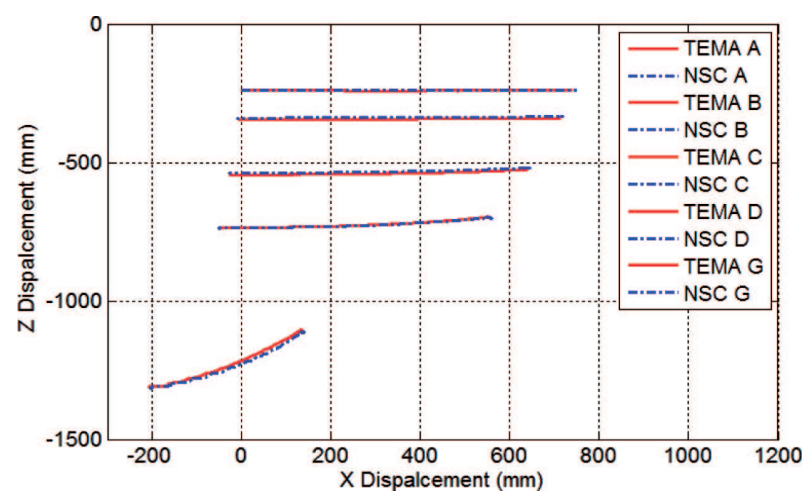

Fig. 7. Positions of the marked points 


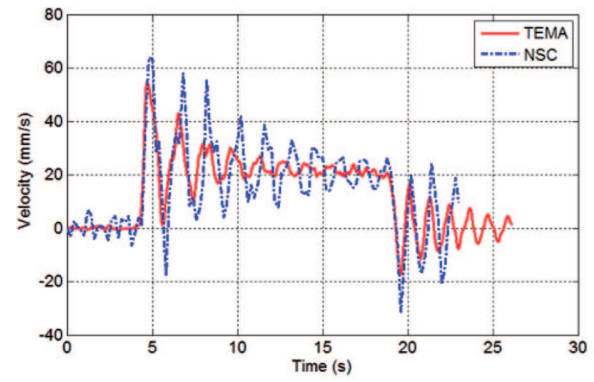

(a) X-directional velocity

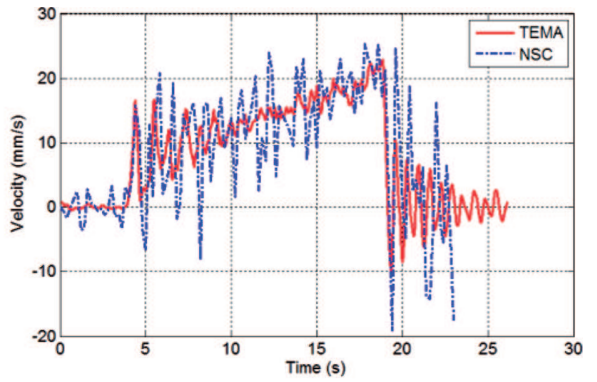

(b) Z-directional velocity

Fig. 8. Velocity of the Point $\mathrm{G}$ during the simulation

The $\mathrm{X}$ - and Z-directional velocities of the Point $\mathrm{G}$ are shown in Fig. 8a and Fig. 8b, respectively. The mean value by numerical simulation code match that of the experiment. However, vibration amplitude by the numerical simulation code is larger than that of the experiment, which indicate other parameters also affect the dynamic motion of the chain. Since the hydrodynamic coefficients are judged from the real experiment through a vertical chain cable, as shown in Fig. 3, the friction forces between the adjacent chain elements are not well reflected during the identification of these coefficients. While, the friction force exists in the catenary chain. In addition, a slight axial-rotation is generated when the catenary chain moving in the fluid in the real experiment, the universal joint between two adjacent chain elements also affects the motions of the chain. Whereas, this effect is not considered by the numerical simulation code. In addition, some marked points are marked on the universal joints, the chain elements in the experiment are not as flexible as those in the numerical simulation code. Finally, these effects play the role of damping in the experiment and reduce the vibration amplitude of the velocity.

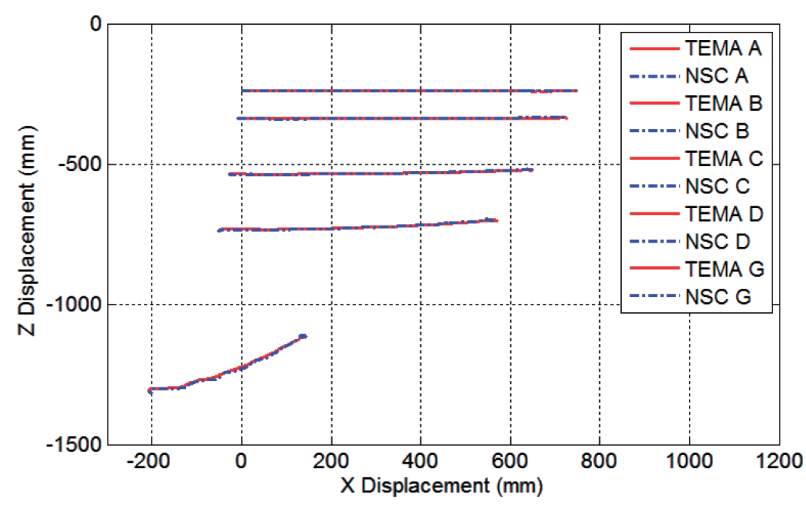

Fig. 9. Positions of marked points with a speed of $100 \mathrm{~mm} / \mathrm{s}$ 
The accuracy of the numerical simulation code is also verified with different speeds. Figure 9 shows the positions of the marked points when the top end of the chain moves with a speed of $100 \mathrm{~mm} / \mathrm{s}$. The marked points are accurately caught by TEMA in the post-processing.

\section{Verification with commercial simulation code}

Commercial simulation code ProteusDS is widely used for the dynamic analysis of mooring system and fishing net. Modelling of the chain is established using the lumped mass method and cubic-spline shape function in ProteusDS. Because the chain mooring is used to fasten the floating platform, a reaction load also acts on the chain from the floating platform according to the Newton's Third Law. An upward force acts on the top end of the chain to act as the loads from floating platform. The force is constant, with a magnitude of $3.5 \mathrm{e} 4 \mathrm{~N}$. The chain is also under influence of the X-directional current and wave in this procedure. The wave height is $2.4 \mathrm{~m}$ and wave period is $8 \mathrm{~s}$, the current is set as a constant speed with a value of $1 \mathrm{~m} / \mathrm{s}$. The initial position of the chain is obtained from a static analysis by ProteusDS. Table 2 lists the properties of the large chain mooring, and the simulation is proceeded $300 \mathrm{~s}$.

Table 2.

Properties of chain in virtual simulation

\begin{tabular}{|c|c|c|}
\hline Parameters & Magnitude & Unit \\
\hline Density & 7800 & $\mathrm{~kg} / \mathrm{m}^{3}$ \\
\hline Length & 500 & $\mathrm{~m}$ \\
\hline Elastic Modulus & 211 & $\mathrm{GPa}$ \\
\hline Drag Coeff. & 1.2 & \\
\hline Added Mass & 1 & \\
\hline Diameter & 0.03 & $\mathrm{~m}$ \\
\hline Element No. & 20 & \\
\hline Upward Force & $3.5 \mathrm{e} 4$ & $\mathrm{~N}$ \\
\hline $1^{\text {st }}$ Node Position & {$[50 ; 0 ;-10]$} & $\mathrm{m}$ \\
\hline $21^{\text {st }}$ Node Position & {$[0 ; 0 ;-500]$} & $\mathrm{m}$ \\
\hline
\end{tabular}

Generally, the positions of the $1^{\text {st }}, 6^{\text {th }}, 10^{\text {th }}$ and $15^{\text {th }}$ nodes are shown by the red, blue, green, and block triangles, respectively in Fig. 10. The positions by the ProteusDS are indicated by triangles towards left, while the positions by the numerical simulation code are towards right. It is hard to notice the slight differences between the results by the numerical simulation code and by the ProteusDS, because of the large outline of the chain. These differences, 


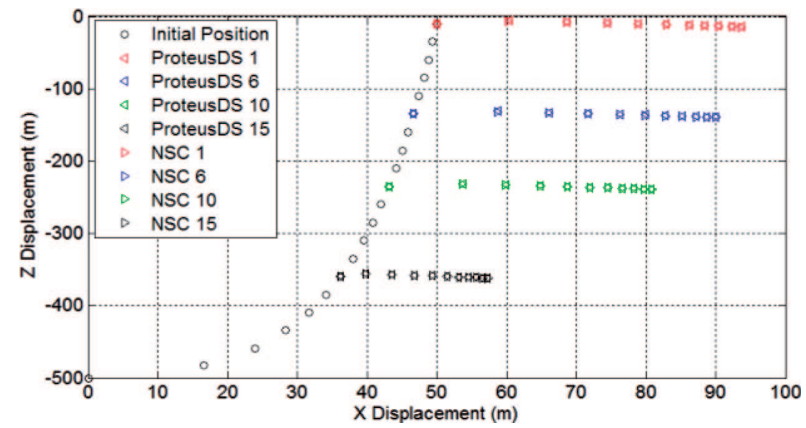

Fig. 10. Positions of the chosen nodes during the simulation

however, could be detected by comparing the Z-directional displacements of the $1^{\text {st }}$ node as shown in Fig. 11. Displacements of the $1^{\text {st }}$ nodes by the numerical simulation code are lower than those by the ProteusDS with a magnitude of $1 \mathrm{~m}$, which indicate the hydrodynamic loads by the numerical simulation code are slightly larger than those by the ProteusDS. Given that the outline of the chain is 500 meters and the water depth is 500 meters, these differences are acceptable. Figure 12 shows the X-displacements of the chosen nodes with respect to time. Wave loads have more effect on motions of

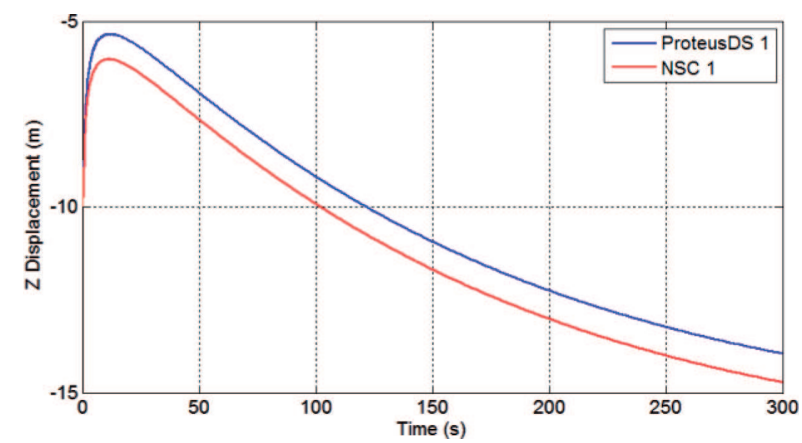

Fig. 11. Z-Displacements of the first node with respect to the time

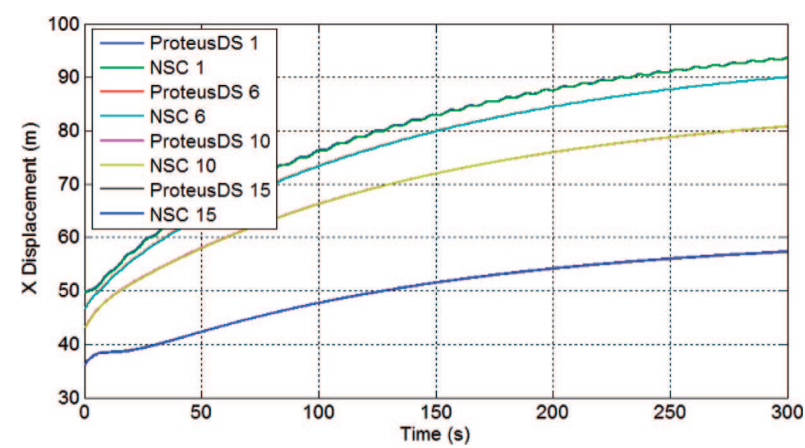

Fig. 12. X-Displacements of chosen nodes with respect to the time 
the chain in the $\mathrm{X}$-direction than in the Z-direction, and this effect decreases with an increase in the water depth. The accuracy of the numerical simulation code is verified by the commercial simulation code.

\section{Conclusions}

An efficient numerical simulation code has been proposed for dynamic analysis of the mooring cables, and its accuracy has been verified by commercial simulation code using cable modeling of small size. Both a real experiment with a small size chain mooring and a virtual simulation with a large size chain mooring are conducted to verify the accuracy commercial simulation code in this paper. The real experiments are carried out in a water tank with a catenary chain. The system error of the experiments is analysed in this paper. The method of processing the experimental data can be valuable references for readers. Both the positons and velocities of the chain by the numerical simulation code are compared with those by the real experiments. The simulation results match with the experimental results well. Additionally, a large size chain modeling is created by both the commercial simulation code and the numerical simulation code with the X-directional linear wave and the constant current. This numerical simulation code also shows a high accuracy in analyzing the large size chain mooring. Therefore, this numerical simulation code is accurate enough to analyse the underwater chain mooring.

\section{Acknowledgements}

This work was supported by the Human Resources Development program (No. 20134030200290) of the Korea Institute of Energy Technology Evaluation and Planning (KETEP) grant funded by the Korea government Ministry of Trade, Industry and Energy.

Manuscript received by Editorial Board, October 05, 2015; final version, March 02, 2016.

\section{REFERENCES}

[1] Jonkman J.M., Butterfield S., Musial W., Scott G.: Definition of a 5-MW reference wind turbine for offshore system development. Technical Report NREL/TP-500-38060, 2009.

[2] Agarwal A.K., Jain A.K.: Dynamic behavior of offshore spar platforms under regular sea waves. Ocean Engineering, 2003, Vol. 30, pp.487-516.

[3] Triantafyllou M.S., Howell C.T.: Nonlinear unstable response of hanging chains. Journal of Sounds and Vibration, 1993, Vol. 162, No. 2, pp. 263-280. 
[4] Jonkman J.M.: Dynamics modeling and loads analysis of an offshore floating wind turbine. Technical Report NREL/TP-500-41958, 2007.

[5] Vazque-Hernandez A.O., Ellwanger G.B., Sagrilo L.V.S.: Long-term response analysis of FPSO mooring system. Applied Ocean Research, 2011, Vol. 33, No. 4, pp. 375-383.

[6] Xu L., Chen, J.: Advantage of polyester mooring for deep water floaters, Proc. of the ASME $201433^{\text {rd }}$ OMAE, 2014, OMAE2014-23976.

[7] Milinazzo F., Wilkie M., Latchman S.A.: An efficient algorithm for simulating the dynamics of towed cable systems. Ocean Engineering, 1987, Vol. 14, No. 6, pp. 513-526.

[8] Buckham B., Nahon M., Seto M., Zhao X., Lambert C.: Dynamic and control of a towed underwater vehicle system, Part I: Model Development, Ocean Engineering, 2003, Vol. 30, pp. 453-470.

[9] Huang S.: Dynamic analysis of three-dimensional marine cable, Ocean Engineering, 1994, Vol. 21(6), pp. 587-605.

[10] James D.: Dynamics Representing attitude: Euler angles, unit quaternions, and rotation vectors, Stanford University, 2006

[11] Hanson A.J., Ma H.: Dynamic Parallel transport approach to curve framing, Indiana University, Tech-report, 1995.

[12] Zhu X.Q., Yoo W.S.: New construction of reference frame for underwater cable, Proc. of the ASME 2014 33rd OMAE, 2014, OMAE2014-24297.

[13] Zhu X.Q., Yoo W.S., Bauchau O.A.: Dynamic analysis of mooring cable fastening a floating sphere on the ocean, Proc. of the ASME 2013 9th DETC, 2013, DETC2013-12693.

[14] Zhu X.Q., Yoo W.S.: New Numerical modeling of a spar platform tethered by a mooring cable. Chinese journal of mechanical engineering, 2015, Vol. 28 (4), pp. 785-792.

[15] TEMA User's Guide, Image System AB, 2009.

[16] DSA Pacific, ProteusDS 2015 Tutorials, Dynamic System Analysis Ltd, 2015.

[17] Feynman R.P., Leighton R.B., Sands M.: The Feynman Lectures on Physics. Desktop Edition Volume I, Chapter 26, 2013.

[18] Boas M.L.L.: Mathematical methods in the physical sciences. Wiley, 2006.

\section{Weryfikacja oprogramowania do symulacji podwodnego cumowania łańcuchowego}

$$
\text { Streszczenie }
$$

Symulacja numeryczna jest ekonomiczną i efektywną metodą w dziedzinie inżynierii okrętowej. Dynamikę lin cumowniczych analizowano numerycznie przy pomocy oprogramowania symulacyjnego stworzonego na podstawie nowego opisu elementu. Celem pracy była weryfikacja dokładności symulacji numerycznej przez porównanie $\mathrm{z}$ eksperymentami $\mathrm{w}$ warunkach rzeczywistych i z komercyjnym oprogramowaniem symulacyjnym. Eksperymenty prowadzono w cysternie z wodą, z użyciem cum łańcuchowych. Wyniki eksperymentów zgadzają się dobrze z wynikami symulacji numerycznej. Dodatkowo, wykonano wirtualną symulację cumowania oceanicznego na długiej cumie łańcuchowej stosując własny program symulacyjny i oprogramowanie komercyjne. Uzyskano dobrą zgodność wyników obydwu symulacji. Tak więc, dokładność opracowanego programu do symulacji podwodnego cumowania łańcuchowego została zweryfikowana zarówno na drodze doświadczalnej, jak i przez porównanie z oprogramowaniem komercyjnym. 